\title{
Modulation of RhoA GTPase Activity Sensitizes Human Cervix Carcinoma Cells to $\gamma$-Radiation by Attenuating DNA Repair Pathways
}

\author{
Juliana H. Osaki, Gisele Espinha, Yuli T. Magalhaes, and Fabio L. Forti \\ Laboratory of Signaling in Biomolecular Systems, Department of Biochemistry, Institute of Chemistry, \\ University of São Paulo, 05508-000 São Paulo, SP, Brazil
}

Correspondence should be addressed to Fabio L. Forti; flforti@iq.usp.br

Received 16 May 2015; Accepted 21 July 2015

Academic Editor: Manoj K. Pandey

Copyright (C) 2016 Juliana H. Osaki et al. This is an open access article distributed under the Creative Commons Attribution License, which permits unrestricted use, distribution, and reproduction in any medium, provided the original work is properly cited.

\begin{abstract}
Radiotherapy with $\gamma$-radiation is widely used in cancer treatment to induce DNA damage reducing cell proliferation and to kill tumor cells. Although RhoA GTPase overexpression/hyperactivation is observed in many malignancies, the effect of RhoA activity modulation on cancer radiosensitivity has not been previously investigated. Here, we generated stable HeLa cell clones expressing either the dominant negative RhoA-N19 or the constitutively active RhoA-V14 and compared the responses of these cell lines with those of parental HeLa cells, after treatment with low doses of $\gamma$-radiation. HeLa-RhoA-N19 and HeLa-RhoA-V14 clones displayed reduced proliferation and survival compared to parental cells after radiation and became arrested at cell cycle stages correlated with increased cellular senescence and apoptosis. Also, Chk1/Chk2 and histone H2A phosphorylation data, as well as comet assays, suggest that the levels of DNA damage and DNA repair activation and efficiency in HeLa cell lines are correlated with active RhoA. In agreement with these results, RhoA inhibition by $\mathrm{C} 3$ toxin expression drastically affected homologous recombination (HR) and nonhomologous end joining (NHEJ). These data suggest that modulation of RhoA GTPase activity impairs DNA damage repair, increasing HeLa cell radiosensitivity.
\end{abstract}

\section{Introduction}

Radiotherapy is widely used in the clinic to inhibit cancer progression and can be administered as a monotherapy or combined with chemotherapy, surgery, and other alternatives. During $\gamma$-radiation radiotherapy, the ionizing radiation applied to tumors is absorbed directly by DNA, inducing DNA damage (including single- and double-strand breaks) [1], which leads to tumor cell death or decreases the effect of tumor cells on adjacent tissues.

In the human cervical carcinoma cell line HeLa, treatment with the bacterial toxin HdCDT induces DNA doublestrand breaks similar to those resulting from $\gamma$-radiation [2]. In this system, induction of DNA double-strand breaks activates the small GTPase RhoA, which regulates a variety of cellular activities involving cytoskeletal reorganization (including cell motility and actin stress fiber formation), as well as cell cycle progression [3]. RhoA overexpression has been reported in breast, colon, lung, and gastric tumors, and it facilitates cancer progression by inducing increased tumor cell motility, proliferation, and survival, as well as a loss of cell polarity [4]. Rho family enzymes interchange between an active form (Rho-GTP) and an inactive form (Rho-GDP). GTPase activation by GTP binding is aided by guanine nucleotide exchange factors (GEFs), which catalyze the exchange of GDP by GTP in the active site. The intrinsic activity of GTP hydrolysis of Rho enzymes (including RhoA) is then activated by GAPs (GTPase activating proteins), leading to conversion of GTP into GDP and Rho inactivation [5].

In HeLa cells, RhoA activation by HdCDT treatment increases HeLa cell survival, and this effect depends on the activity of the ataxia telangiectasia mutated (ATM) serine/threonine protein kinase [2], a DNA damage repair 
protein activated as a response to DNA double-strand breaks (such as those induced by ionizing radiation) [6]. Although these data suggest the existence of a "cross talk" between RhoA and DNA repair pathways, the effect of RhoA activity modulation on the sensitivity of cancer cells to radiotherapy has not been examined to date.

In this study, we analyzed the effect of modulation of RhoA activity in the response to $\gamma$-radiation $(0.5,5$, and 15 Gy) treatment, in HeLa cells. We generated stable HeLa cell lines that express a constitutively active RhoA (HeLa-RhoAV14) or a dominant negative RhoA (HeLa-RhoA-N19). These mutants are analogous to the Ras-V12 (constitutively active) and Ras-N17 (dominant negative) mutants found in $~ 25 \%$ of all human cancers, in marked contrast to RhoA mutations, which are rarely found $[7,8]$. Our results show that cells expressing either the constitutively active or the dominant negative RhoA mutants are less resistant to the effects of $\gamma$ radiation than parental HeLa cells and have reduced ability to proliferate and survive after treatment. These data correlated with the reduced activation of DNA damage response and repair pathways and efficiency of DNA damage repair, in cells with reduced RhoA activity.

\section{Materials and Methods}

2.1. Cell Lines. The human cervical carcinoma cell line HeLa (CCL-2; ATCC, Manassas, VA, USA) was maintained in Dulbecco's Modified Eagle Medium (DMEM; Invitrogen, Waltham, MA, USA) supplemented with $10 \%$ fetal bovine serum (FBS; Cultilab, Campinas, SP, Brazil), at $37^{\circ} \mathrm{C}$ and $5 \% \mathrm{CO}_{2}$, in a humidified incubator.

2.2. Cell Treatments by $\gamma$-Radiation. HeLa cells and clones were treated with three different doses $(0.5,2,5$, and $15 \mathrm{~Gy})$ of gamma $(\gamma)$ ionizing radiation (Co60-Gammacell 220, Atomic Energy of Canada Limited (AECL), Ontario, Canada) at the Nuclear and Energy Research Institute (IPEN, SP, Brazil). But for some experiments dose-response curves were performed, while for others only one dose was used, according to the cell viability (unpublished results, not shown) and the duration of the experiment.

2.3. Generation of Sublines of RhoA-N19 and RhoA-V14 Mutants from HeLa Cells. To produce HeLa cell sublines stably expressing RhoA mutants, constructs containing the recombinant retroviral $\mathrm{pCM}$ vector and $\mathrm{CDNA}$ sequences for the constitutively active RhoA-V14 (Ala to Val substitution at position 14) or the dominant negative RhoA-N19 (Thr to Asp substitution at position 19) were packaged into recombinant retrovirus particles using the Phoenix system $(\phi N \mathrm{NX}$ cells, kindly donated by Gary P. Nolan, Stanford University, CA, USA). Subconfluent HeLa cells seeded in $10 \mathrm{~cm}$ dishes (in DMEM/10\% FBS) were infected with the recombinant retrovirus particles in the presence of $8 \mu \mathrm{g} / \mathrm{mL}$ of polybrene [9]. After infection, cells were selected for approximately 30 days with $500 \mu \mathrm{g} / \mathrm{mL}$ of G418, and isolated colonies, representing clones of HeLa-RhoA-N19 and HeLa-RhoAV14, were collected and maintained in DMEM/10\% FBS with $100 \mu \mathrm{g} / \mathrm{mL}$ of $\mathrm{G} 418$ until freezing or further use.
2.4. Active RhoA Pull-Down Assay. To measure RhoA activity, we used a RhoA-GTP pull-down protocol adapted from Ren et al., 1999 [10]. HeLa cells were lysed in RIPA buffer (50 mmol/L Tris-HCl, pH 7.2, containing 1\% Triton X-100, $0.5 \%$ sodium deoxycholate, $0.1 \% \mathrm{SDS}, 500 \mathrm{mmol} / \mathrm{L} \mathrm{NaCl}$, $10 \mathrm{mmol} / \mathrm{L} \mathrm{MgCl}_{2}, 1 \mathrm{mM} \mathrm{Na} \mathrm{Vo}_{4}, 1 \mathrm{mM} \mathrm{NaF}, 2 \mu \mathrm{g} / \mathrm{mL}$ leupeptin, pepstatin, aprotinin, and $1 \mathrm{mmol} / \mathrm{L}$ phenylmethylsulfonyl fluoride, or PMSF) (all from Sigma-Aldrich, Saint Louis, MO, USA), and cell lysates were incubated with Glutathione-Sepharose beads (GE, Healthcare, Cleveland, $\mathrm{OH}$, USA) bound to the RBD-GST fusion protein (RhoA binding domain of the Rhotekin protein, kindly donated by Gary M. Bokoch, The Scripps Research Institute, La Jolla, CA, USA) for $90 \mathrm{~min}$ at $4^{\circ} \mathrm{C}$. Then, beads were recovered by centrifugation $\left(3000 \mathrm{rpm}\right.$, for $3 \mathrm{~min}$ at $4^{\circ} \mathrm{C}$ ) and washed 3 times with buffer B $(50 \mathrm{mmol} / \mathrm{L}$ Tris- $\mathrm{HCl}, \mathrm{pH} 7.2$, containing $1 \%$ Triton X-100, $150 \mathrm{mmol} / \mathrm{L} \mathrm{NaCl}, 10 \mathrm{mmol} / \mathrm{L} \mathrm{MgCl}_{2}$, $1 \mathrm{mM} \mathrm{Na} \mathrm{Vo}_{4}, 1 \mathrm{mM} \mathrm{NaF}, 10 \mu \mathrm{g} / \mathrm{mL}$ leupeptin, aprotinin, and $0.1 \mathrm{mmol} / \mathrm{L}$ PMSF). RhoA-GTP bound to RBD-GSTSepharose beads was resolved on 13\% SDS-PAGE gels, transferred to nitrocellulose membranes and analyzed using a monoclonal anti-RhoA antibody (26C4, from Santa Cruz Biotechnology, Santa Cruz, CA, USA), as described below (see Section 2.11).

2.5. Growth Curves. For population growth analysis, HeLa cells were seeded in $35 \mathrm{~mm}$ dishes $\left(3.5 \times 10^{4}\right.$ cells/dish $)$ and allowed to adhere at $37^{\circ} \mathrm{C}$ (with $5 \% \mathrm{CO}_{2}$ ), for $24 \mathrm{~h}$. Then cells were exposed to 0.5 or 5 Gy of $\gamma$-radiation and reincubated at $37^{\circ} \mathrm{C}$. Cell samples were collected in duplicate every $24 \mathrm{~h}$ after $\gamma$-radiation, for five consecutive days, and cells were counted manually in a Fuchs-Rosenthal chamber.

2.6. Clonogenic Assays. For clonogenic assays, HeLa cells were seeded in 60 - $\mathrm{mm}$ dishes $\left(2 \times 10^{3}\right.$ cells/dish $)$ and allowed to adhere at $37^{\circ} \mathrm{C}$ (with $5 \% \mathrm{CO}_{2}$ ) for $24 \mathrm{~h}$. Then, cells were exposed to $0.5,5$, or $15 \mathrm{~Gy}$ of $\gamma$-radiation and reincubated at $37^{\circ} \mathrm{C}$ for $10-12$ days. Colony foci were fixed in $10 \%$ formaldehyde in PBS for $10 \mathrm{~min}$, stained with $0.5 \%$ crystal violet in PBS for $5 \mathrm{~min}$ (both at room temperature), and counted manually.

2.7. Cell Cycle Analysis. For cell cycle analysis, HeLa cells were plated in $35-\mathrm{mm}$ dishes $\left(3.5 \times 10^{5}\right.$ cells/dish $)$ and allowed to adhere at $37^{\circ} \mathrm{C}$ (with $5 \% \mathrm{CO}_{2}$ ) for $24 \mathrm{~h}$. After $\gamma$-radiation, cells were harvested by trypsinization, washed in PBS, and fixed in $80 \%$ ethanol in PBS. Then, cells were stained with $10 \mu \mathrm{g} / \mathrm{mL}$ propidium iodide (PI) and stored at $4^{\circ} \mathrm{C}$. Samples were run in a Beckman Coulter FC500 MPL cytometer (Brea, CA, USA), and flow cytometry data were analyzed using WinMDI 2.8 software (Purdue University Cytometry Laboratories, West Lafayette, IN, USA).

2.8. Apoptosis Assay. To estimate apoptosis, HeLa cells were plated in $35-\mathrm{mm}$ dishes $\left(1.5 \times 10^{5}\right.$ cells/dish), for $24 \mathrm{~h}$, and treated with $5 \mathrm{~Gy}$ or $15 \mathrm{~Gy}$ of $\gamma$-radiation, or with $60 \mathrm{~J} / \mathrm{m}^{2}$ ultraviolet C (UVC; positive control for apoptosis induction). Then, adhered and suspended cells were harvested by 
successive rounds of PBS washing-trypsinization-centrifugation, $48 \mathrm{~h}$ or $72 \mathrm{~h}$ after $\gamma$-radiation. Harvested cells were resuspended in Annexin-V binding buffer (50 mM HEPES, $\mathrm{pH}$ 7.4, containing $0.7 \mathrm{M} \mathrm{NaCl}$ and $12.5 \mathrm{mM} \mathrm{CaCl} 2$ ) for a final density of $1 \times 10^{6}$ cells $/ \mathrm{mL}$, and $5 \mu \mathrm{L}$ Annexin-VFITC (BD Biosciences, Franklin Lakes, NJ, USA) and $1.5 \mu \mathrm{L}$ propidium iodide $(1 \mathrm{mg} / \mathrm{mL})$ were added to $100-\mu \mathrm{L}$ aliquots of cell suspension $\left(1 \times 10^{5}\right.$ cells). Samples were incubated for $15 \mathrm{~min}$ at room temperature (and protected from light), and then $400 \mu \mathrm{L}$ of Annexin-V binding buffer was added to each sample, and cells were analyzed by flow cytometry in a FACSVerse (BD Biosciences, Franklin Lakes, NJ, USA). Flow cytometry data were analyzed on the Kaluza 1.3 Flow Analysis software (Beckman Coulter, Brea, CA, USA).

2.9. Senescence-Associated $\beta$-Galactosidase Assay. Cell senescence was estimated using a senescence-associated $\beta$ galactosidase assay, as described by Dimri et al., 1995 [11]. HeLa cells $\left(3.0 \times 10^{4}\right.$ cells/dish, in $35-\mathrm{mm}$ dishes) (Corning, New York, NY, USA) were allowed to adhere at $37^{\circ} \mathrm{C}$ (with $5 \% \mathrm{CO}_{2}$ ) for $24 \mathrm{~h}$, prior to treatment with 0.5 , 5, or $15 \mathrm{~Gy}$ of $\gamma$-radiation. Then, cells were incubated for $96 \mathrm{~h}$ at $37^{\circ} \mathrm{C}$, fixed in $2 \%$ formaldehyde $/ 0.2 \%$ glutaraldehyde in PBS for $3 \mathrm{~min}$, washed in PBS, and stained for $18 \mathrm{~h}$ at $37^{\circ} \mathrm{C}$ with $2 \mathrm{~mL} /$ dish of $\mathrm{X}$-gal staining solution $(30 \mathrm{mmol} / \mathrm{L}$ $\mathrm{PBS} /$ citric acid $\left(\mathrm{pH}\right.$ 6) containing $5 \mathrm{mmol} / \mathrm{L} \mathrm{K}_{3} \mathrm{Fe}(\mathrm{CN})_{6}$, $2 \mathrm{mmol} / \mathrm{L} \mathrm{MgCl}{ }_{2}, 150 \mathrm{mmol} / \mathrm{L} \mathrm{NaCl}, 5 \mathrm{mmol} / \mathrm{L} \mathrm{K}_{4} \mathrm{Fe}(\mathrm{CN})_{6}$, and $1 \mathrm{mg} / \mathrm{mL} \mathrm{X-gal).} \mathrm{Then,} \mathrm{samples} \mathrm{were} \mathrm{washed} \mathrm{twice} \mathrm{in}$ PBS and kept at $4^{\circ} \mathrm{C}$ prior to analysis, by direct counting of $\beta$-galactosidase-positive/negative cells $\left(1 \times 10^{3}\right.$ cells/dish, in duplicate), in an inverted Olympus microscope (Olympus, Tokyo, Japan).

2.10. Alkaline Comet Assay. The alkaline comet assay was performed as described by Singh et al., 1998 [12], with modifications. HeLa cells were seeded in $35-\mathrm{mm}$ dishes $(2 \times$ $10^{5}$ cells/dish) and were allowed to adhere at $37^{\circ} \mathrm{C}$ (with $5 \%$ $\mathrm{CO}_{2}$ ) for $24 \mathrm{~h}$, before $\gamma$-radiation with $5 \mathrm{~Gy}$. After treatment, cells were harvested by trypsinization, mixed with $0.5 \%$ low-melting point agarose, and $100 \mu \mathrm{L}$ of this mixture was pipetted onto glass slides with $1.5 \%$ normal-melting point agarose. Then, cells were lysed with lysis buffer $(10 \mathrm{mmol} / \mathrm{L}$ Tris, pH 10, containing $2.5 \mathrm{mmol} / \mathrm{L} \mathrm{NaCl}, 100 \mathrm{mmol} / \mathrm{L}$ EDTA, $1 \%$ Triton X-100, and 10\% DMSO, all from Sigma-Aldrich, Saint Louis, MO, USA) for $24 \mathrm{~h}$ at $4^{\circ} \mathrm{C}$ and in the dark. Samples were denatured in alkaline electrophoresis buffer ( $300 \mathrm{mmol} / \mathrm{L} \mathrm{NaOH}, 1 \mathrm{mmol} / \mathrm{L}$ EDTA, $\mathrm{pH}>13$ ) for $25 \mathrm{~min}$, and then electrophoresis was performed at $25 \mathrm{~V}$ and $300 \mathrm{~mA}$, for $30 \mathrm{~min}$. After electrophoresis, slides were washed 3 times ( $5 \mathrm{~min} /$ wash $)$ in neutralizing buffer $(0.4 \mathrm{mmol} / \mathrm{L}$ Tris- $\mathrm{HCl}$, $\mathrm{pH}$ 7.5), DNA was stained with $2 \mu \mathrm{g} / \mathrm{mL}$ ethidium bromide, and comets (from 50 cells/slide, in duplicate) were imaged using a fluorescence microscope Olympus IX51 (Olympus, Shinjuku, Tokyo, Japan). Comet assay data were analyzed using the software Komet 6.0 (Andor, Technology, Belfast, BT, UK).
2.11. Western Blotting. For Western blotting, HeLa cells were lysed with RIPA buffer (see Section 2.4), and $50 \mu \mathrm{g}$ of protein was mixed with Laemmli sample buffer [13] and resolved in $12 \%$ SDS-PAGE gels. Proteins were transferred to nitrocellulose membrane (Millipore, Billerica, MA, USA), and membranes were blocked in TBS-T with $5 \%$ milk, for $1 \mathrm{~h}$ at room temperature. Then, membranes were incubated with one of the following primary antibodies diluted in TBS-T: anti-phospho-Chk1 Ser345 (Cat. number 2341), antiphospho-Chk2 Thr-68 (Cat. number 2661), or anti-phosphoH2AX Ser139 (Cat. number 9718) polyclonal/monoclonal antibodies from Cell Signaling (Danvers, MA, USA) or an anti- $\alpha$-Tubulin polyclonal/monoclonal antibody (B-7, Santa Cruz Biotechnology, Santa Cruz, CA, USA). Membranes were incubated with appropriate species-specific IRDye (Infrared Dye) secondary antibodies (680 or $800 \mathrm{~nm}$, diluted to $1: 15000$ in TBS-T) for $1 \mathrm{~h}$ and visualized and analyzed (by band density quantification) using an Odyssey Infrared Imaging System and the Odyssey V3.0 software (both from Li-COR Biosciences, Lincoln, NE, USA).

2.12. Inhibition of RhoA Activity by the C3 Toxin. HeLa cells were transiently transfected with the eukaryotic expression vector pEF-myc (Invitrogen) containing the C3 toxin coding sequence (plasmid kindly provided by Professor Dr. Gary Bokoch, The Scripps Research Institute, La Jolla, CA, USA). HeLa cells were transfected using Lipofectamine 2000 (Invitrogen), according to the manufacturer's instructions, and then plated into 100-mm dishes (for immunoblotting experiments) or 35-mm dishes (for comet assays) and allowed to grow until $\sim 80 \%$ confluence. The cells were incubated for 24 hours, prior to RhoA activation analysis (see Section 2.4), and after this time the cells were exposed to $5 \mathrm{~Gy}$ of $\gamma$ radiation and analyzed according to the previously described experiments.

2.13. Homologous Recombination (HR) and Nonhomologous End Joining (NHEJ) Assays. The rates of HR and NHEJ were estimated using HeLa cells stably expressing DR-GFP and EJ-GFP, respectively, as described by Gunn and Stark with modifications [14]. To produce HeLa-DR-GFP and HeLaEJ5-GFP stable cell lines, subconfluent HeLa cells grown in $60-\mathrm{mm}$ dishes were transfected using $7.5 \mu \mathrm{g}$ Lipofectamine 2000 (Invitrogen, Waltham, MA, USA) and $3.5 \mu \mathrm{g}$ of DR-GFP or EJ5-GFP plasmids [14], in DMEM with 10\% FBS. Transfectants were selected and isolated using $5 \mu \mathrm{g} / \mathrm{mL}$ of puromycin and maintained in DMEM/10\% FBS supplemented with $1 \mu \mathrm{g} / \mathrm{mL}$ of puromycin.

For HR and NHEJ assays, approximately $2 \times 10^{5} \mathrm{HeLa}-$ DR-GFP and HeLa-EJ5-GFP cells were seeded in $35-\mathrm{mm}$ dishes and allowed to adhere at $37^{\circ} \mathrm{C}$ (with $5 \% \mathrm{CO}_{2}$ ) for $24 \mathrm{~h}$. Then, cells were transfected with $4 \mu \mathrm{g}$ of the I-SceI expression vector or an empty vector $(\mathrm{EV})$, alone or in combination with $2 \mu \mathrm{g}$ of pEF-myc-C3 (using $2 \mu \mathrm{g}$ of Lipofectamine 2000; Invitrogen, Waltham, MA, USA). Cells were harvested $72 \mathrm{~h}$ after transfection, and the percentage of GFP-positive cells was determined by flow cytometry in a FACSVerse cytometer (BD Biosciences, Franklin Lakes, NJ, USA). 
2.14. Statistical Analysis. Comparisons between treatments were performed by Student's $t$-test (for paired data) or by ANOVA (for multiple groups), using the Prism 6.0 software, and differences were considered statistically significant when $P<0.05$.

\section{Results}

3.1. Expression of Dominant Negative or Constitutively Active RhoA Prevents the Increase in Active RhoA Levels by $\gamma$ Radiation. To evaluate if the activation of the small GTPase RhoA has a role in the response to $\gamma$-radiation in cancer cells, we generated stable clones of HeLa cells expressing either the constitutively active HeLa-RhoA-V14 or the dominant negative HeLa-RhoA-N19 RhoA mutants. Cells from both clones appeared to spread on the surface of culture flasks more effectively than parental HeLa cells (Figure 1(a)). Analysis of RhoA activity by a pull-down assay for the active RhoAGTP form [15] showed that HeLa-RhoA-N19 and parental HeLa cells had similar basal levels of active RhoA, while HeLa-RhoA-V14 cells had higher levels of active RhoA, as expected for cells expressing a constitutively active RhoA mutant (Figure 1(b)). RhoA-GTP levels increased after $\gamma$ radiation in parental HeLa cells (Figure 1(b)). In contrast, we detected no further RhoA activation in cells expressing RhoA-N19 or RhoA-V14, after $\gamma$-radiation (Figure 1(b)).

The RhoA GTPase is a key regulator of cell migration via cytoskeletal reorganization [16]. Thus, we also performed scratch assays in confluent cell monolayers, to evaluate the effect of mutant RhoA expression on cell migration (see Supplementary Figure S1 in Supplementary Material available online at http://dx.doi.org/10.1155/2016/6012642). For cells grown in medium containing $10 \%$ FBS, the migration rate of those expressing the dominant negative RhoA-N19 was considerably reduced (43\%) compared with that of parental HeLa or HeLa-RhoA-V14 cells (100\% migration). In serumfree conditions (0\% FBS), HeLa-RhoA-N19 migrated only $5 \%, 24 \mathrm{~h}$ after serum starvation, but migration rates in $10 \%$ FBS (after serum starvation) were similar to those observed in cells that had not been serum-starved prior to migration. However, in starving conditions, HeLa-RhoAV14 cells displayed reduced migration (27\%) compared with parental HeLa cells (Supplementary Figure S1). These results suggest that the expression of either RhoA-V14 or RhoAN19 promotes an imbalance in the RhoA activity in HeLa cells, despite the presence of normal to high basal levels of active RhoA. While the migration of parental or HeLa-RhoAV14 cells was only significantly affected by high doses of $\gamma$ radiation ( $15 \mathrm{~Gy})$, treatments as low as $5 \mathrm{~Gy}$ of $\gamma$-radiation reduced significantly the migration of HeLa-RhoA-N19 cells in medium with $10 \%$ FBS (Supplementary Figure S2). Overall, the scratch assay data suggest that, despite the persistent levels of RhoA-GTP in cells expressing either dominant negative or constitutively active RhoA mutants, these cells had altered RhoA activity, judging from their reduced migration ability, and this effect was particularly evident in cells expressing the dominant negative RhoA-V14 mutant, after $\gamma$-radiation treatment. Thus, the migration data also indicate that the HeLa-RhoA-V14 and HeLa-RhoA-N19 cell lines are valid models for the study of RhoA activity modulation after radiation.

\subsection{Expression of RhoA Mutants Alters HeLa Cell Proliferation} and Survival Rates after $\gamma$-Radiation. To investigate the effect of RhoA activity modulation on cell proliferation and survival after exposure to low doses ( 0.5 and $5 \mathrm{~Gy})$ of $\gamma$ radiation, we performed growth curves and clonogenic assays of HeLa cells expressing mutant RhoA proteins. HeLa-RhoAN19 and HeLa-RhoA-V14 displayed a reduced doubling time compared to parental HeLa cells ( 3.1 and $\sim 2.6$ days, resp.). We observed a clear reduction in the proliferation of all cell lines after exposure to $5 \mathrm{~Gy}$ of $\gamma$-radiation, and proliferation inhibition was observed earlier (between 2 and 3 days after radiation) in HeLa-RhoA-N19 and HeLa-RhoAV14 cultures, compared with parental HeLa cells (Figure 1(c)). No significant reduction in cell proliferation was observed after exposure to 0.5 Gy of $\gamma$-radiation (Figure 1(c)).

In clonogenic (colony formation) assays, both HeLaRhoA-N19 and HeLa-RhoA-V14 displayed decreased survival, with a reduction of $\sim 50 \%$ in the number of colonies in untreated cells, and this sensitivity to the effects of $0.5 \mathrm{~Gy}$ of $\gamma$ radiation was relatively well maintained compared with $\mathrm{HeLa}$ cells. When exposed to $5 \mathrm{~Gy}$ of $\gamma$-radiation, HeLa-RhoAV14 and HeLa-RhoA-N19 were significantly more sensitive than parental HeLa cells, with a reduction of $\sim 70 \%$ and $\sim 80 \%$, respectively, in the number of colonies, compared with parental cells subjected to the same treatment (Figure 1(d)). These data suggest that HeLa cells expressing either a dominant negative or a constitutively active RhoA mutant are more sensitive to low doses of $\gamma$-radiation than parental HeLa cells.

\subsection{Expression of RhoA Mutants Leads to Differential Cell} Cycle Arrest with Increased Senescence and Apoptosis Induction. Cell cycle analysis (by flow cytometry using PI) of irradiated cells suggested that, after exposure to 15 Gy of $\gamma$ radiation, cells with constitutively high levels of activated RhoA (HeLa-RhoA-V14) remain arrested in S and G2/M, whereas HeLa cells expressing the dominant negative RhoAN19 remain predominantly in the $\mathrm{G} 1$ and $S$ phases of the cell cycle (Figure 1(e)). As expected, we observed a marked arrest of HeLa cells in the G2/M phase of the cell cycle after treatment with high (15 Gy) dose of $\gamma$-radiation (Figure 1(e)).

The radiation-induced arrest at different cell cycle stages correlates with the distinct types of antiproliferative effects observed in HeLa cell lines expressing RhoA mutants, after radiation treatment (Figure 2). Cells expressing HeLa-RhoAN19, expected to be deficient in RhoA activity, display higher senescence levels at lower doses of 0.5 and 5 Gy of $\gamma$-radiation, which correlates with their preferential arrest at G1 and S phases (Figure 2(a)). These cells also showed increased apoptosis 48 and $72 \mathrm{~h}$ after exposure to the highest (15 Gy) dose of $\gamma$-radiation (Figure 2(b)). Similarly, all doses of radiation treatment led to increased senescence in cells expressing the constitutively active HeLa-RhoA-V14 mutant, compared with parental HeLa cells (but not with cells expressing RhoA-N19), although the highest senescence levels were observed only after treatment with the highest dose (15 Gy) of $\gamma$-radiation (Figure 2(a)). These results correlate with the preferential 


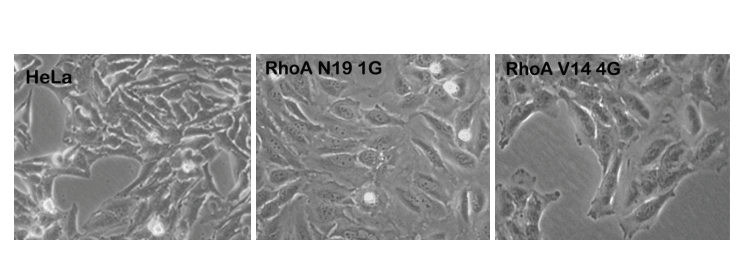

(a)
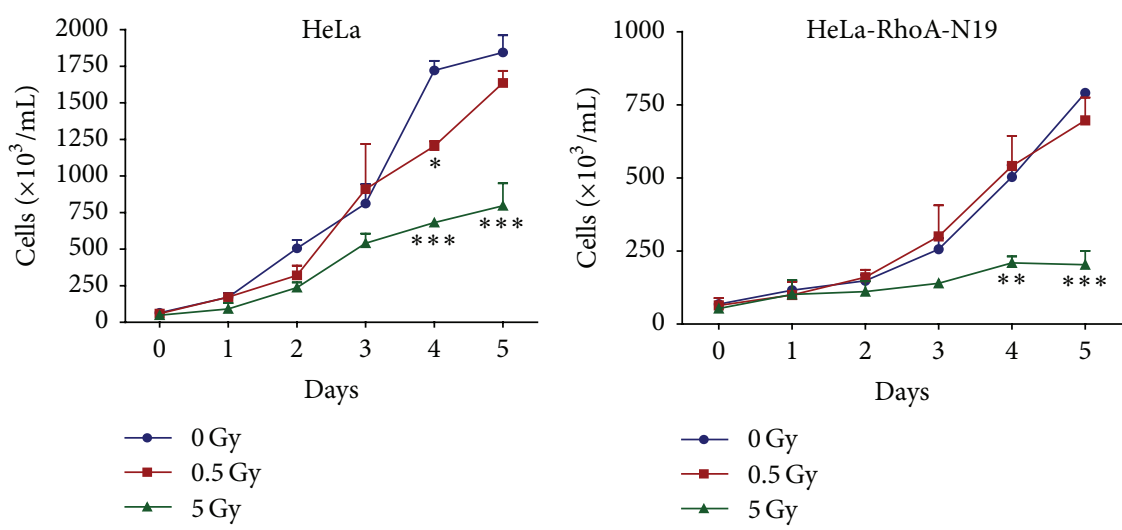

(c)

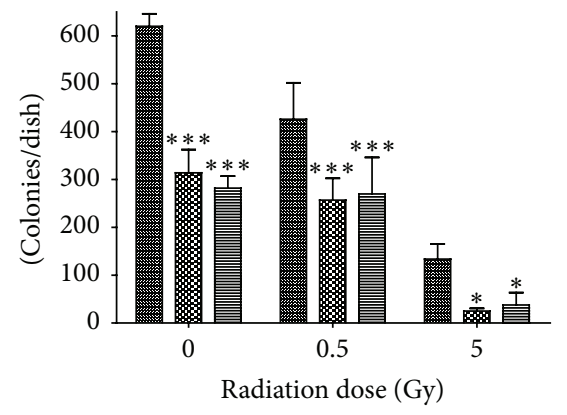

\% $\mathrm{HeLa}$

E. HeLa-RhoA-N19

HeLa-RhoA-V14

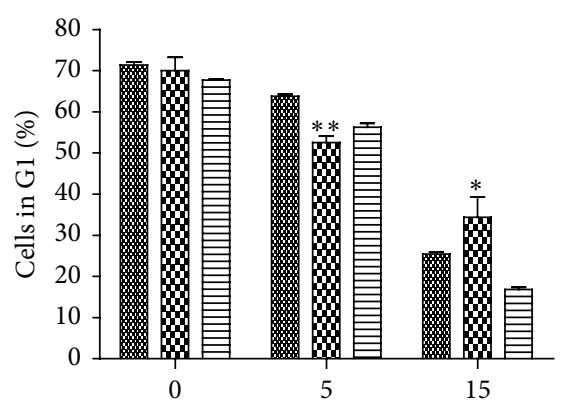

(Gy)

\$ $\mathrm{HeLa}$

DI. HeLa-RhoA-N19

HeLa-RhoA-V14

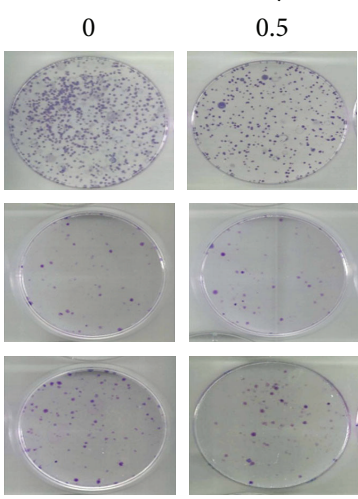

(d)

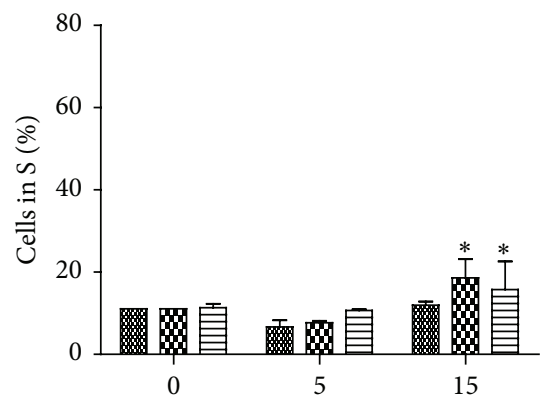

(Gy)

W. HeLa

DI. HeLa-RhoA-N19 HeLa-RhoA-V14

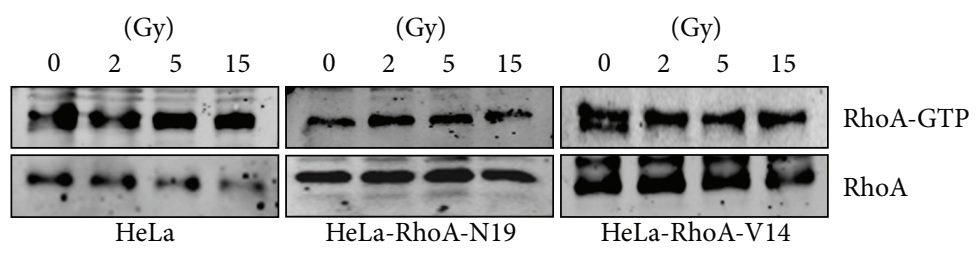

(b)
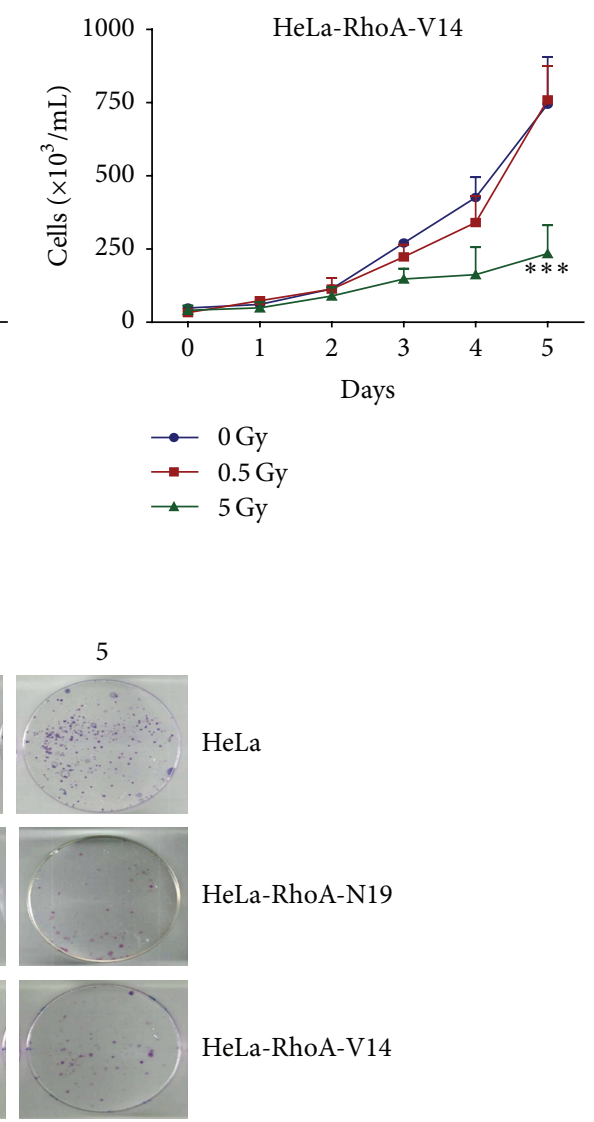

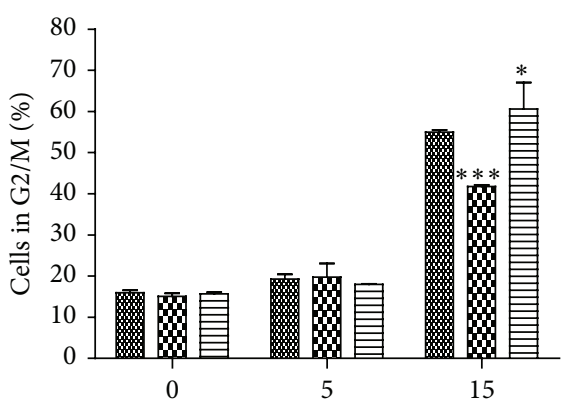

(Gy)

W. HeLa

Di. HeLa-RhoA-N19 HeLa-RhoA-V14

(e)

FIGURE 1: Morphological Rho activity and proliferation analyses of parental and clonal HeLa cell lines expressing RhoA-N19 or RhoA-V14 mutants after $\gamma$-radiation. (a) Morphology of parental and derived HeLa cell lines. (b) Immunoblotting of pull-down assays for active RhoA (RhoA-GTP) in different cell lines. (c) and (d) Growth curves (c) and clonogenic assays (d) in cell lines under positive or negative modulation of RhoA activity. (e) Cell cycle profiles by flow cytometry analysis (using PI staining) of HeLa cell lines after exposure to different doses of $\gamma$-radiation. Graphs display mean \pm SD of at least three independent experiments. ${ }^{*} P<0.05,{ }^{* *} P<0.005$, and ${ }^{* * *} P<0.001$ between clones and parental HeLa cells in the same treatment conditions (by ANOVA). 


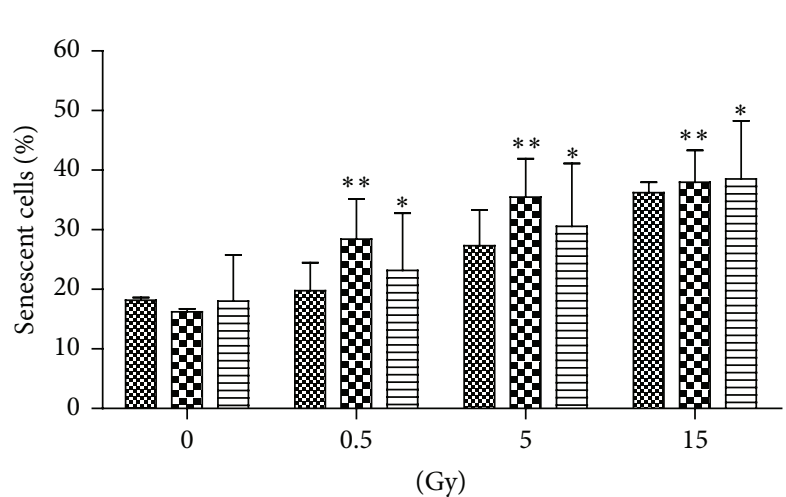

$\% \mathrm{HeLa}$

0 HeLa-RhoA-N19

E HeLa-RhoA-V14

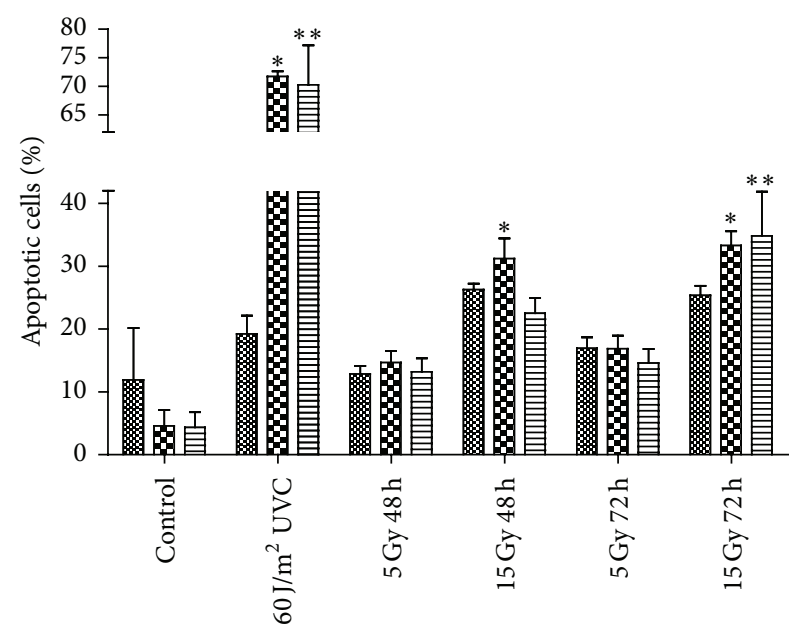

\&国 HeLa

DeLa-RhoA-N19

HeLa-RhoA-V14

(a)

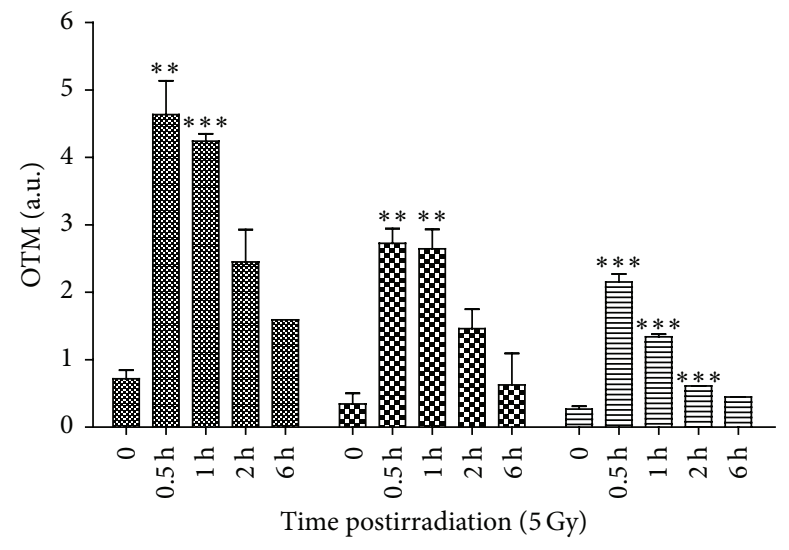

\% $\mathrm{HeLa}$

HeLa-RhoA-N19

HeLa-RhoA-V14

(c)

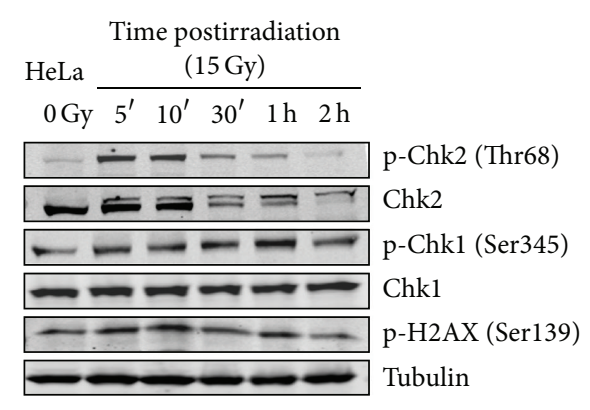

Time postirradiation

HeLa-RhoA-N19

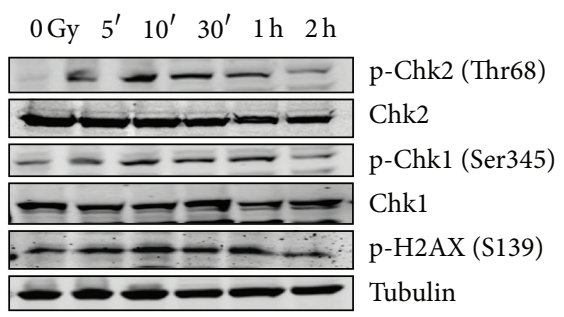

HeLa-RhoA-V14

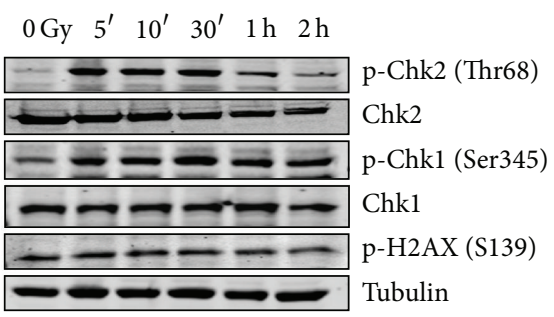

(d)

FIGURE 2: Cell death and DNA damage response and repair analyses in HeLa cells expressing RhoA mutants, after $\gamma$-radiation treatment. (a) Quantification of senescent cells, by a senescence-associated $\beta$-galactosidase assay, performed $96 \mathrm{~h}$ after radiation. (b) Quantification of apoptotic cell death after radiation, by Annexin $-\mathrm{V}$ and propidium iodide staining (Annexin $\mathrm{V}^{+} / \mathrm{PI}^{+}$cells were considered apoptotic). (c) Estimation of DNA damage and repair efficiency following radiation, by the olive tail moment (OTM, in arbitrary units) measurements from comet assays. (d) Immunoblotting analysis of phosphorylated Chk1/Chk2 and histone H2AX levels in the different HeLa cell lines, after exposure to $15 \mathrm{~Gy}$ of $\gamma$-radiation (and using $\alpha$-Tubulin as loading control). Graphs and immunoblots are representative of three independent experiments. ${ }^{*} P<0.01,{ }^{* *} P<0.05$, and ${ }^{* * *} P<0.001$ between clones and parental HeLa cells and ${ }^{*} P<0.005$ between treated and untreated conditions (by ANOVA). 
arrest of HeLa-RhoA-V14 at S and G2/M and with an increase in apoptotic cell death after exposure to $15 \mathrm{~Gy}$ of $\gamma$-radiation, especially at the longer time-point of $72 \mathrm{~h}$ posttreatment (Figure 2(b)). Taken together, the cell cycle analysis, apoptosis, and senescence data suggest that modulation of RhoA activity leads to arrest at different stages of the cell cycle, leading to the induction of different levels of senescence or apoptosis.

\subsection{Modulation of RhoA Activity in HeLa Cells Affects DNA} Damage Repair Induction and DNA Damage Response (DDR) Protein Activation. To investigate if modulation of RhoA activity affects DNA repair after radiation treatments, we performed comet assays at different time-points after exposure to $5 \mathrm{~Gy}$ of $\gamma$-radiation. All three HeLa cell lines exhibited a peak of fragmented DNA (i.e., an increase in the olive tail moment, or OTM) $0.5 \mathrm{~h}$ after radiation, and this peak was $\sim 6$ - and $\sim 8$-fold higher than the basal levels (in nonirradiated cells), for parental HeLa and RhoA mutant-expressing cells, respectively (Figure 2(c)). Although fragmented DNA levels decreased up to $6 \mathrm{~h}$ after radiation in all three HeLa cell lines, DNA repair (i.e., a statistically significant reduction in OTM) could be detected as early as $1 \mathrm{~h}$ after radiation treatment in parental HeLa and in HeLa-RhoA-V14 cells (Figure 2(c)). In contrast, DNA repair could be detected from $2 \mathrm{~h}$ after $\gamma$-radiation treatment in HeLa-RhoA-N19 cells, suggesting that DNA damage repair is delayed in this cell line, which is expected to have reduced RhoA activity (Figure 2(c)).

To examine a possible correlation between the efficiency of DNA repair and the phosphorylation of DNA damage responses (DDR) proteins, we exposed parental HeLa, HeLaRhoA-N19, and HeLa-RhoA-V14 cells to 15 Gy of $\gamma$-radiation and monitored the activation (by phosphorylation) of the checkpoint proteins Chk1 and Chk2, as well as the appearance of a marker for double-strand DNA breaks (p-Ser139 $\mathrm{H} 2 \mathrm{AX}$ ), for up to $2 \mathrm{~h}$ after radiation (Figure $2(\mathrm{~d})$ ). After treatments, we observed a reduction in the phosphorylation levels of both Chk1 (Ser345) and Chk2 (Thr-68) in cells expressing the dominant negative RhoA-N19 mutant, while cells expressing the constitutively active RhoA-V14 displayed overactivation of Chk1/Chk2; both responses were different from those observed in parental HeLa cells. Thus, the levels of Chk1/Chk2 phosphorylation obtained for the three cell lines correlate with their RhoA-GTP levels. In contrast, the phosphorylation of H2AX (Ser139), which peaked between $5 \mathrm{~min}$ and $1 \mathrm{~h}$ after radiation and returned to basal levels $2 \mathrm{~h}$ after treatment, was not significantly affected by the modulation of RhoA activity (Figure 2(d)).

3.5. C3 Toxin-Mediated Downregulation of RhoA Activity Impairs DNA Repair and Overactivates DDR Proteins. To confirm that decreased RhoA activity reduces DNA repair efficiency, as suggested by the comet assay data on HeLa cells expressing dominant negative RhoA, we performed a potent and persistent inhibition of RhoA in parental HeLa cells by transfection with a plasmid encoding the C3 toxin. To that we transfected HeLa cells with a plasmid driving constitutive expression of the C3 toxin, an exoenzyme secreted by the bacterium Clostridium botulinum and capable of selectively inhibiting the activation of RhoA, RhoB, and RhoC GTPases [17-19]. As expected, expression of the C3 toxin had a strong effect on cell morphology, $24 \mathrm{~h}$ after transfection, and reduced RhoA-GTP to residual levels (Figure 3(a)). Also, comet assay results suggest that $\mathrm{C} 3$ toxin expression increased HeLa cell sensitivity to DNA damage by $\gamma$-radiation (5 Gy) (Figure 3(b)). After C3 toxin expression, the levels of DNA breaks increased by $\sim 10$-fold at $0.5 \mathrm{~h}$ after radiation, and DNA damage repair could be detected from $2 \mathrm{~h}$ after radiation, similar to the response observed in the HeLa Rho-N19 cells (Figure 2(c)); however, DNA damage appeared more persistent in HeLa cells expressing C3, judging from the levels of damage remaining up to $6 \mathrm{~h}$ after $\gamma$-radiation (Figure 3(b), compared with HeLa, in Figure $2(\mathrm{c}))$. These results are in agreement with the overactivation of phospho-Chk1 (Ser345) after $\gamma$-radiation (15 Gy) treatment, in cells expressing the C3 toxin, which seems to reflect the persistence of high phosphoH2AX (Ser139) levels in HeLa cells (Figure 3(c)).

To investigate the effect of C3 toxin-mediated RhoA inhibition on the activity of specific DNA repair pathways, we generated HeLa cell lines capable of GFP-based detection of homologous recombination (HR, via the reporter EJ5-GFP) or nonhomologous end joining (NHEJ, via the reporter gene DR-GFP), after expression of the endonuclease I-SceI, which cleaves on specific sequences in the reporter gene plasmidial DNA [14]. Interestingly, in cells expressing both the C3 toxin and I-SceI, the levels of double-strand break repair by either HR or NHEJ were significantly reduced compared with those observed in cells expressing the I-Sce-I enzyme only, reaching similar levels to those observed in controls (empty vector, or $\mathrm{EV}$, and EV + C3) (Figures 3(d) and 3(e)). Endogenous RhoA inhibition by $\mathrm{C} 3$ expression affected both repair pathways: while HR was completely inhibited, NHEJ was partially disrupted in cells where the endogenous repair machinery was specifically recruited to reporter gene sequences (EJ-GFP and DR-GFP, resp.) integrated in the genome. Altogether, these results strongly support the involvement of RhoA in DNA damage response and repair mechanisms.

\section{Discussion}

RhoA GTPase is overexpressed and overactivated in cancer and is involved in cancer progression, directly regulating cell proliferation, survival, and invasion [3, 4]. Our results, using stable HeLa cell lines expressing either a constitutively active RhoA (RhoA-V14) or a dominant negative version of this protein (RhoA-N19), suggest that RhoA GTPase activity also regulates cancer cell sensitivity to $\gamma$-radiation, by affecting basic DNA repair mechanisms. Despite the fact that HeLa cells have been used as a good model for our hypothesis and this whole work has been done solely on it, we believe that our results do not reflect a cell linedependent phenomenon because unpublished results (not shown) performed in metastatic melanoma MeWo cell line culminate in similar cellular responses.

We observed that HeLa cells have high basal level of RhoA GTPase in the active state (RhoA-GTP) and that the activity of RhoA was modulated accordingly (up or down) in both mutant clones. RhoA-GTP levels increased 


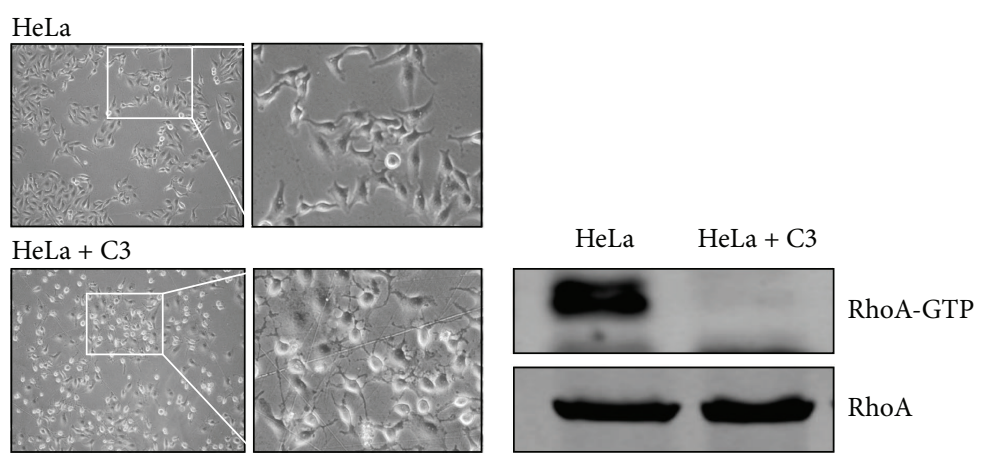

(a)

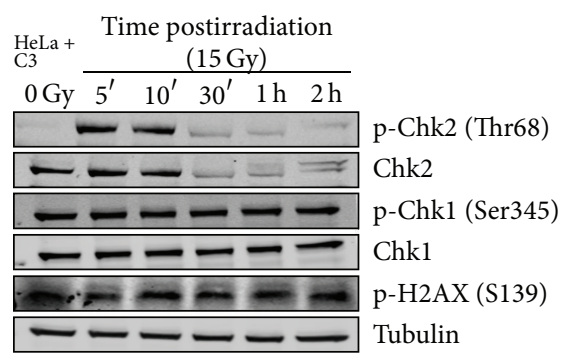

(c)

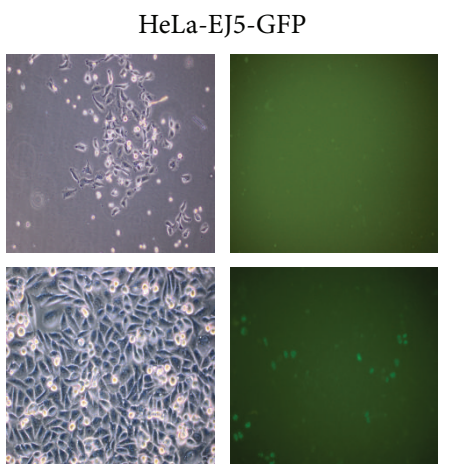

(d)

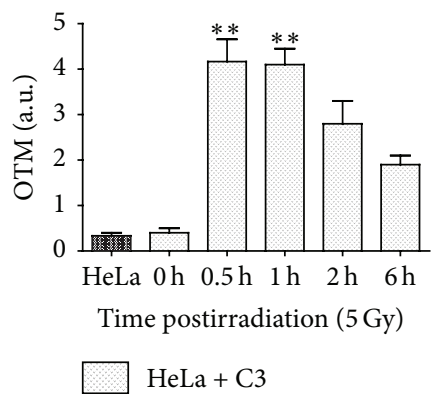

(b)

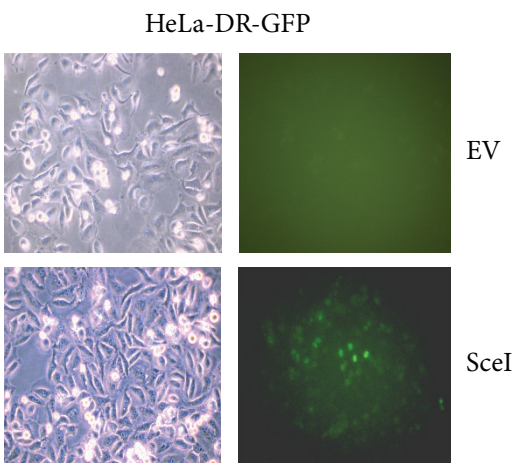

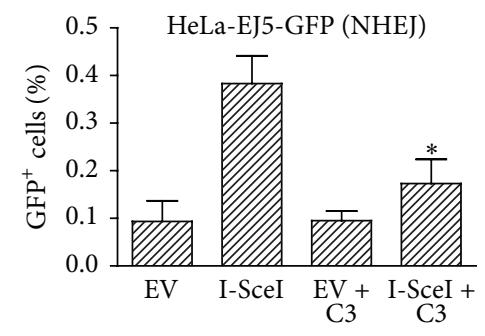

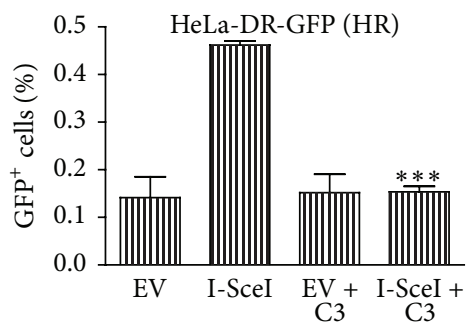

(e)

FIGURE 3: Inhibition of RhoA activity by C3 toxin expression strongly affects DNA damage response, including global and specific DNA repair mechanisms in HeLa cells, following $\gamma$-radiation. (a) Dendritic morphology of HeLa cells (HeLa + C3 images) associated with decreased RhoA-GTP levels (on the right), $24 \mathrm{~h}$ after transfection with a plasmid for C3 toxin expression. Images on the right are insets from those on the left, 200x. (b) Estimates of DNA damage and repair efficiency (by olive tail moment, or OTM, measurements from comet assays) in HeLa cell expressing the C3 toxin, following $\gamma$-radiation. (c) Immunoblotting analysis of the effects of $\gamma$-radiation (15 Gy) on phosphorylated Chk1/Chk2 and histone H2AX levels in HeLa cells expressing the C3 toxin (using $\alpha$-Tubulin as a loading control). (d) and (e) Assays for GFP-based detection of homologous recombination (HR, using HeLa-DR-GFP) or nonhomologous end joining (NHEJ, using HeLa-EJ5GFP) after DNA damage induced by I-SceI restriction enzyme expression. (d) Phase contrast (left) and green fluorescence (right) images of cells transfected with a plasmid for I-SceI expression (I-SceI), or with an empty vector (EV), showing the appearance of GFP-positive cells indicative of HR (HeLa-EJ5-GFP) or NHEJ (HeLa-DR-GFP), $72 \mathrm{~h}$ after transfection. (e) Quantification of HR and NHEJ assays, with (EV $+\mathrm{C} 3$ and I-SceI + C3 groups) or without (EV and I-SceI groups) concomitant C3 toxin expression. Graphs (with mean \pm SD values) and immunoblots are representative of three independent experiments. ${ }^{*} P<0.05,{ }^{* *} P<0.001$, and ${ }^{* * *} P<0.005$, between treated and untreated conditions (by ANOVA).

in response to either $\gamma$-radiation activation or serum stimuli (not shown). The high basal levels of RhoA-GTP observed here in cervical adenocarcinoma HeLa cells are similar to those reported for other cancer cell lines, including the breast cancer cell line MDA-MB-231 [20], and also in colorectal cancer cell lines and tumor samples [21]. The RhoA GTPase directly regulates cytoskeletal dynamics via actin polymerization, mediating cell adhesion and migration $[16,22]$.
In glioblastoma multiforme tumors, radiation-induced activation of RhoA increases cell migration and invasive potential [23]. Our study extends these results, showing that cells expressing the dominant negative RhoA-N19 display decreased migration rates, both in the presence and in the absence of FBS, and also following $\gamma$-radiation. The opposite was observed for HeLa cells expressing the constitutively active RhoA-V14, indicating that in HeLa cells with decreased 
RhoA activity migration is inhibited by ionizing radiation, while RhoA overactivation enables cells to migrate after radiation treatment, in agreement with the results reported by Ridley in 2006 [24].

When compared with those displayed by parental HeLa cells, the proliferation and survival responses to $\gamma$-radiation of both HeLa cell lines expressing RhoA mutants are interesting, since they suggest that "fine-tuning" of RhoA activity impacts on DNA repair efficiency. Similar results were reported for canine T23 MDCK cells, where downregulation of RhoA activity by expression of RhoA-N19 decreased cell survival after toxin-mediated DNA doublestrand break induction [2], showing that RhoA GTPase activity is important for survival after DNA damage in these cells. However, we observed that cells expressing the dominant negative RhoA-N19 and those expressing the constitutively active RhoA-V14 were equally susceptible to decreases in proliferation and survival, following $\gamma$-radiation. Interestingly, differential modulation of RhoA activity in HeLa cells led to population arrest at distinct stages of the cell cycle, which correlated with changes in the levels of cellular senescence and apoptosis observed in each cell line, following $\gamma$-radiation. These different "cell-fate" decisions seem to depend on the levels of RhoA activity, which in turn affect DNA damage sensing by the DDR pathway, directly reflecting in cell cycle phase-dependent triggering of cell proliferation inhibition followed by cell death. These data are in agreement with studies showing that DNA damage activates RhoA in an ATM-dependent manner and that RhoA activation is important for cell survival and proliferation, after treatment with low doses of $\gamma$-radiation [2, 25].

The effectiveness of radiotherapy treatment of human tumors is based (almost entirely) on the inability of cancer cells to repair radiation-induced DNA damage [2]. Given that the presence of DNA damage induces RhoA activation and triggers DNA repair mechanisms $[2,26]$, it is not surprising that DNA repair was more efficient in cells expressing the constitutively active RhoA-V14 mutant than in those expressing the dominant negative RhoA-N19, although DNA repair in HeLa-RhoA-V14 was still less efficient than that observed in parental HeLa cells. We detected increased levels of DNA damage relative to basal conditions for both mutant clones. We also observed increased levels of DNA damage and slow repair after inhibition of endogenous RhoA activity by C3 toxin expression, and RhoA inhibition drastically reduced the activity of the DNA repair pathways $H R$ and NHEJ in HeLa cells. These data strongly suggest that RhoA GTPase is involved (possibly indirectly) in the regulation of DNA repair pathways, particularly in early repair. The similarities between our results and those obtained with HdCDT-induced DNA damage provide further support to our hypothesis that cytosolic RhoA signaling modulates nuclear genome integrity mechanisms $[2,27,28]$.

Finally, our data on the effects of RhoA activity modulation on classical DNA damage response pathways suggest that RhoA is indirectly involved in the regulation of Chk1 and Chk2 activation after $\gamma$-radiation, because Chk1 (Ser345) and Chk2 (Thr-68) phosphorylation appeared attenuated

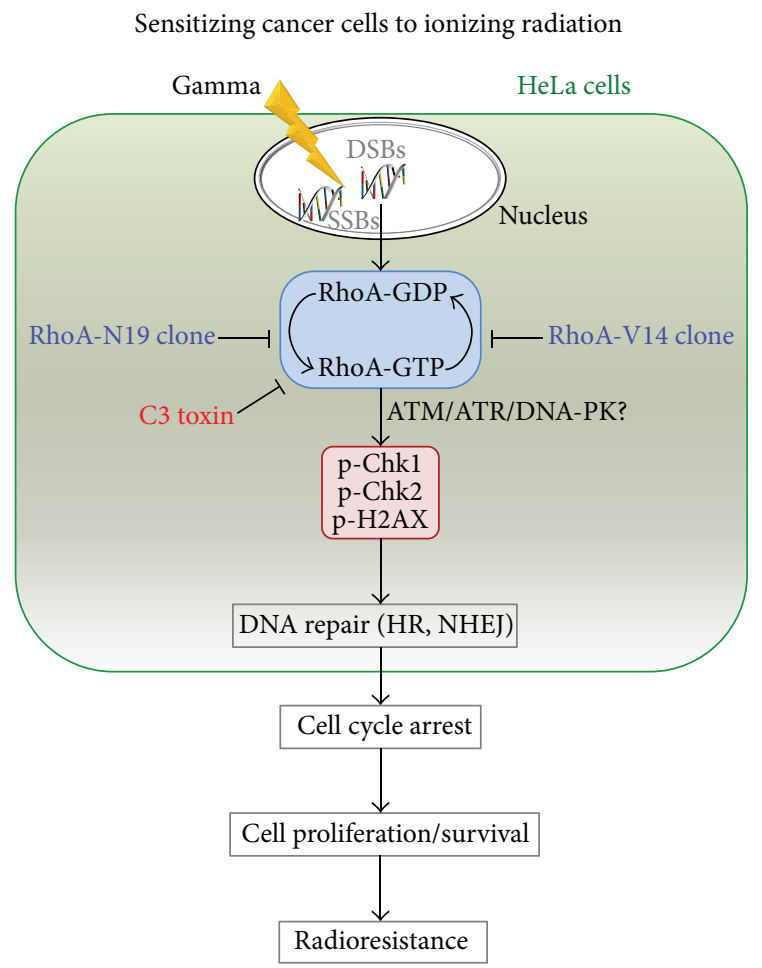

FIgURE 4: Model of the effects of RhoA activity modulation on global and specific DNA repair mechanisms, leading to increased cell proliferation or cell death, and reflecting in the radioresistance levels of cancer cells.

in HeLa-RhoA-N19 cells and increased in HeLa-RhoA-V14, after exposure to $\gamma$-radiation.

Chk1/Chk2 protein kinases are activated in response to DNA damage and are involved in DNA damage repair [29]. Pharmacological inhibition of Chk1/Chk2 induces cellular radiosensitivity, impairing DNA repair and triggering mitotic catastrophe, in the human colon cancer cell line HT-29 [30]. Thus, the attenuated phosphorylations of Chk1 and Chk2 in cells deficient in RhoA signaling may have impaired DNA repair (by HR and NHEJ) in these cells, which would explain the reductions in survival and proliferation, the specific cell cycle arrest pattern, and the increased levels of senescence and apoptosis observed in these cells. Overall, our data support the existence of a "cross talk" between RhoA signaling and DNA damage response and repair pathways in cancer cells (Figure 4), which may contribute to increased radioresistance. Importantly, these findings raise the interesting possibility that, in the clinic, the combination of chemotherapy using RhoA inhibitors followed by radiotherapy may lead to positive associations, for specific stages of cervical cancers.

\section{Conclusions}

Our findings provide strong evidence that positive or negative modulation of RhoA activity increases HeLa cell's sensitivity to $\gamma$-radiation treatment and therefore points to a possible clinical association of chemotherapy, using RhoA inhibitors, 
followed by radiotherapy sections for different stages of cervical cancers.

\section{Conflict of Interests}

The authors declare that there is no potential conflict of interests.

\section{Authors' Contribution}

Conception and design were done by Fabio L. Forti. Development of methodology was done by Juliana H. Osaki, Yuli T. Magalhaes, and Gisele Espinha. Acquisition of data was done by Juliana H. Osaki, Yuli T. Magalhaes, and Gisele Espinha. Analysis and interpretation of data were performed by Juliana H. Osaki, Gisele Espinha, and Fabio L. Forti. Writing, review, and/or revision of the paper were made by Juliana H. Osaki and Fabio L. Forti. Study supervision was done by Fabio L. Forti.

\section{Acknowledgments}

The authors thank Andressa P. Costa, Juliana R. Domingos, Benedita Oliveira, and Viviane Q. Machtura for technical assistance. They also thank Dr. Margarida M. Hamada, Dr. Elizabeth Somessari, and the staff from CTRD-IPEN/CNEN (São Paulo, SP, Brazil) for conducting $\gamma$-radiation on their samples. They thank Professor Marisa Gennari de Medeiros for allowing them to perform comet assays in her laboratory. Additionally, they thank the Publicase staff and editors for their editing services. This research was supported by the Brazilian agency FAPESP through a Young Investigator Fellowship, no. 2008/58264-5, to Fabio L. Forti. Juliana H. Osaki is the recipient of an FAPESP Ph.D. Fellowship (142668/2009-5), GE is the recipient of a CAPES Master Fellowship (2011/05822-3), and Yuli T. Magalhaes is an undergraduate student recipient of $\mathrm{CNPq}$ Scientific Initiation Fellowship. All research projects in our laboratory have been also supported by the Brazilian agency CAPES through the Graduate Program in Biochemistry of the Chemistry Institute. The final publication of this paper was supported by the CAPES/PROEX funds and by the Sao Paulo State Research Foundation (FAPESP) through Grant no. 2015/18341-4 to Fabio L. Forti.

\section{References}

[1] A. C. Begg, F. A. Stewart, and C. Vens, "Strategies to improve radiotherapy with targeted drugs," Nature Reviews Cancer, vol. 11, no. 4, pp. 239-253, 2011.

[2] T. Frisan, X. Cortes-Bratti, E. Chaves-Olarte, B. Stenerlöw, and M. Thelestam, "The Haemophilus ducreyi cytolethal distending toxin induces DNA double-strand breaks and promotes ATMdependent activation of RhoA," Cellular Microbiology, vol. 5, no. 10, pp. 695-707, 2003.

[3] A. B. Jaffe and A. Hall, "Rho GTPases: biochemistry and biology," Annual Review of Cell and Developmental Biology, vol. 21, pp. 247-269, 2005.
[4] F. M. Vega and A. J. Ridley, "Rho GTPases in cancer cell biology," The FEBS Letters, vol. 582, no. 14, pp. 2093-2101, 2008.

[5] J. L. Bos, H. Rehmann, and A. Wittinghofer, "GEFs and GAPs: critical elements in the control of small G proteins," Cell, vol. 129, no. 5, pp. 865-877, 2007.

[6] S. Ashwell and S. Zabludoff, "DNA damage detection and repair pathways-recent advances with inhibitors of checkpoint kinases in cancer therapy," Clinical Cancer Research, vol. 14, no. 13, pp. 4032-4037, 2008.

[7] R.-G. Qiu, J. Chen, F. Mccormick, and M. Symons, "A role for Rho in Ras transformation," Proceedings of the National Academy of Sciences of the United States of America, vol. 92, no. 25, pp. 11781-11785, 1995.

[8] L. A. Feig and G. M. Cooper, "Inhibition of NIH 3T3 cell proliferation by a mutant ras protein with preferential affinity for GDP," Molecular and Cellular Biology, vol. 8, no. 8, pp. 3235$3243,1988$.

[9] É. T. Costa, F. L. Forti, T. G. F. Matos et al., "Fibroblast growth factor 2 restrains Ras-driven proliferation of malignant cells by triggering RhoA-mediated senescence," Cancer Research, vol. 68, no. 15, pp. 6215-6223, 2008.

[10] X.-D. Ren, W. B. Kiosses, and M. A. Schwartz, "Regulation of the small GTP-binding protein Rho by cell adhesion and the cytoskeleton," The EMBO Journal, vol. 18, no. 3, pp. 578-585, 1999.

[11] G. P. Dimri, X. Lee, G. Basile et al., "A biomarker that identifies senescent human cells in culture and in aging skin in vivo," Proceedings of the National Academy of Sciences of the United States of America, vol. 92, no. 20, pp. 9363-9367, 1995.

[12] N. P. Singh, M. T. McCoy, R. R. Tice, and E. L. Schneider, "A simple technique for quantitation of low levels of DNA damage in individual cells," Experimental Cell Research, vol. 175, no. 1, pp. 184-191, 1988.

[13] U. K. Laemmli, "Cleavage of structural proteins during the assembly of the head of bacteriophage T4," Nature, vol. 227, no. 5259, pp. 680-685, 1970.

[14] A. Gunn and J. M. Stark, "I-SceI-based assays to examine distinct repair outcomes of mammalian chromosomal double strand breaks," Methods in Molecular Biology, vol. 920, pp. 379391, 2012.

[15] T. Reid, T. Furuyashiki, T. Ishizaki et al., "Rhotekin, a new putative target for Rho bearing homology to a serine/threonine kinase, PKN, and rhophilin in the Rho-binding domain," The Journal of Biological Chemistry, vol. 271, no. 23, pp. 13556-13560, 1996.

[16] D. Spiering and L. Hodgson, "Dynamics of the rho-family small GTPases in actin regulation and motility," Cell Adhesion and Migration, vol. 5, no. 2, pp. 170-180, 2011.

[17] A. Rohrbeck, T. Kolbe, S. Hagemann, H. Genth, and I. Just, "Distinct biological activities of C3 and ADP-ribosyltransferasedeficient C3-E174Q," FEBS Journal, vol. 279, no. 15, pp. 26572671, 2012.

[18] E. Sahai and M. F. Olson, "Purification of TAT-C3 exoenzyme," Methods in Enzymology, vol. 406, pp. 128-140, 2006.

[19] K. Aktories, C. Wilde, and M. Vogelsgesang, "Rho-modifying $\mathrm{C}_{3}$-like ADP-ribosyltransferases," Reviews of Physiology, Biochemistry and Pharmacology, vol. 152, pp. 1-22, 2004.

[20] J.-Y. Pillé, C. Denoyelle, J. Varet et al., "Anti-RhoA and antiRhoC siRNAs inhibit the proliferation and invasiveness of MDA-MB-231 breast cancer cells in vitro and in vivo," Molecular Therapy, vol. 11, no. 2, pp. 267-274, 2005. 
[21] F. Leve and J. A. Morgado-Díaz, "Rho GTPase signaling in the development of colorectal cancer," Journal of Cellular Biochemistry, vol. 113, no. 8, pp. 2549-2559, 2012.

[22] M. Parri and P. Chiarugi, "Rac and Rho GTPases in cancer cell motility control," Cell Communication and Signaling, vol. 8, article 23, 2010.

[23] G. G. Zhai, R. Malhotra, M. Delaney et al., "Radiation enhances the invasive potential of primary glioblastoma cells via activation of the Rho signaling pathway," Journal of Neuro-Oncology, vol. 76, no. 3, pp. 227-237, 2006.

[24] A. J. Ridley, "Rho GTPases and cell migration," Journal of Cell Science, vol. 114, no. 15, pp. 2713-2722, 2001.

[25] L. Guerra, R. Guidi, I. Slot et al., "Bacterial genotoxin triggers FEN1-dependent RhoA activation, cytoskeleton remodeling and cell survival," Journal of Cell Science, vol. 124, no. 16, pp. 2735-2742, 2011.

[26] A. J. Hawkins, S. E. Golding, A. Khalil, and K. Valerie, "DNA double-strand break-induced pro-survival signaling," Radiotherapy and Oncology, vol. 101, no. 1, pp. 13-17, 2011.

[27] J. Fahrer, J. Huelsenbeck, H. Jaurich et al., "Cytolethal distending toxin (CDT) is a radiomimetic agent and induces persistent levels of DNA double-strand breaks in human fibroblasts," DNA Repair, vol. 18, no. 1, pp. 31-43, 2014.

[28] R. Guidi, L. Guerra, L. Levi et al., "Chronic exposure to the cytolethal distending toxins of Gram-negative bacteria promotes genomic instability and altered DNA damage response," Cellular Microbiology, vol. 15, no. 1, pp. 98-113, 2013.

[29] B.-B. S. Zhou and S. J. Elledge, "The DNA damage response: putting checkpoints in perspective," Nature, vol. 408, no. 6811, pp. 433-439, 2000.

[30] O. Riesterer, F. Matsumoto, L. Wang et al., "A novel Chk inhibitor, XL-844, increases human cancer cell radiosensitivity through promotion of mitotic catastrophe," Investigational New Drugs, vol. 29, no. 3, pp. 514-522, 2011. 


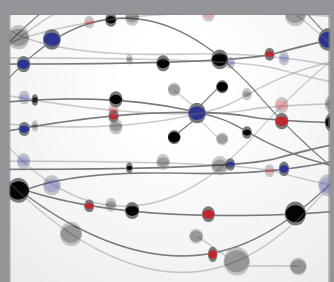

The Scientific World Journal
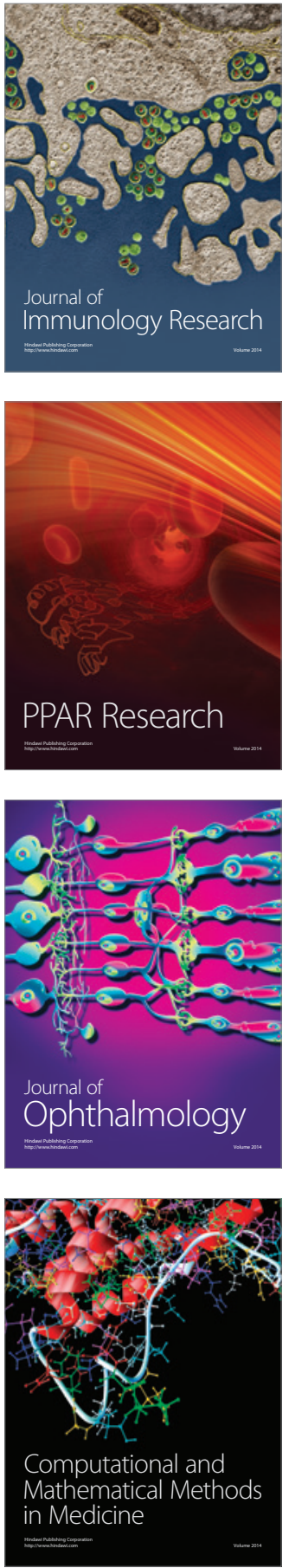

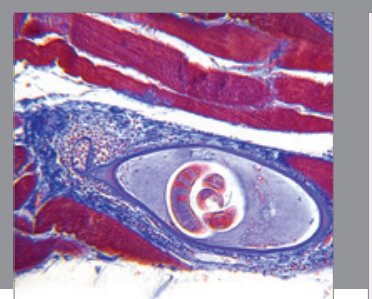

Gastroenterology Research and Practice

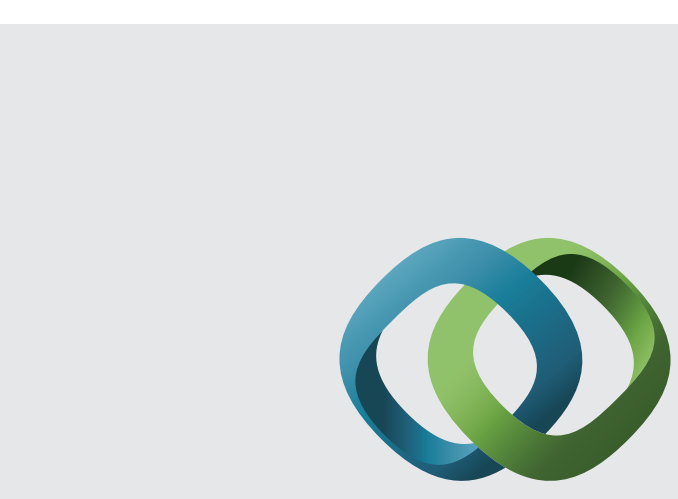

\section{Hindawi}

Submit your manuscripts at

http://www.hindawi.com
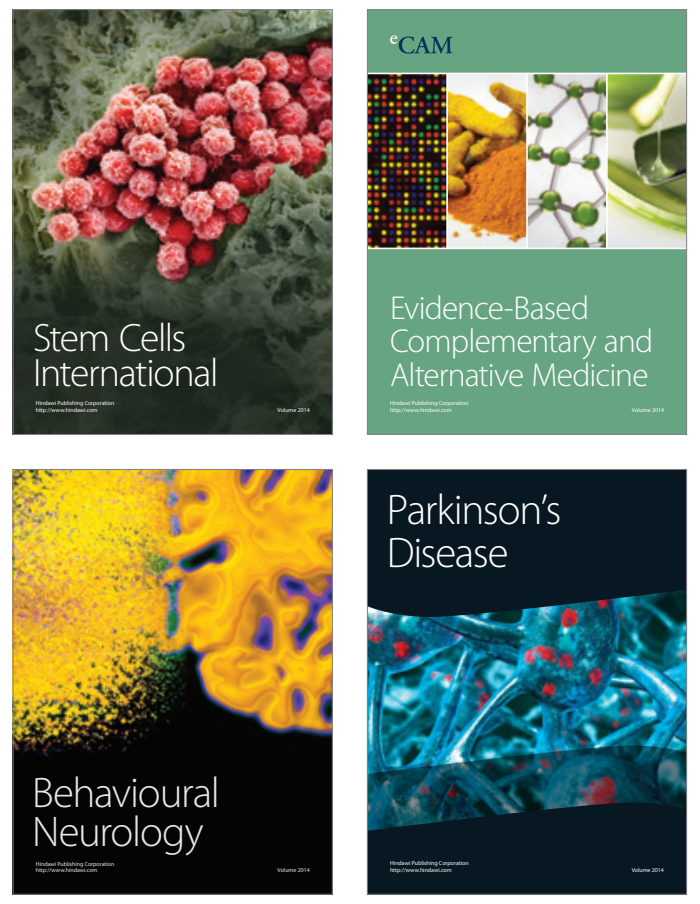
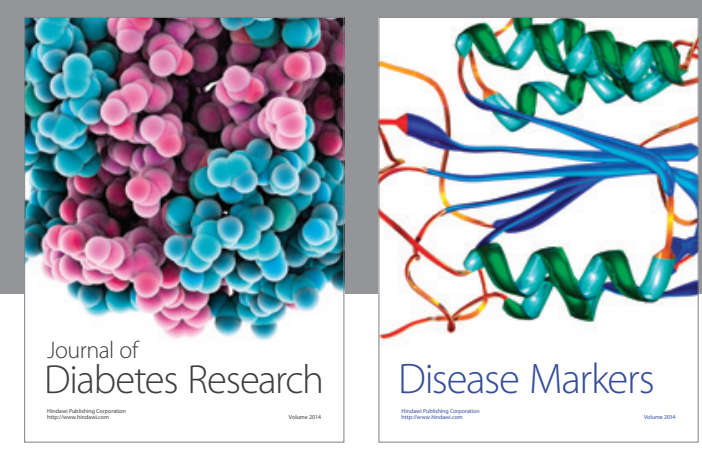

Disease Markers
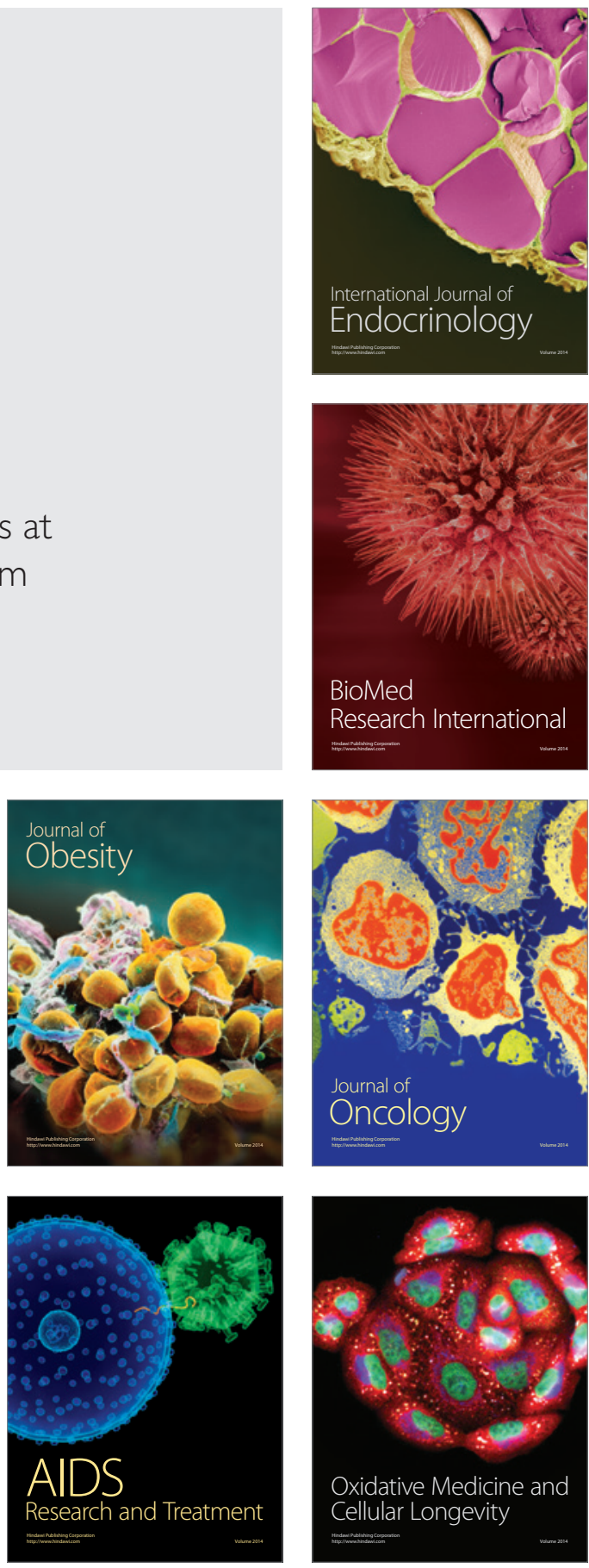